\title{
Assessment of the Internal Instability for Granular Soils Subjected to Seepage
}

\author{
Marx Ferdinand Ahlinhan*, Marius Bocco Koube, Codjo Edmond Adjovi \\ Ecole des Sciences et Techniques du Bâtiment et de la Route (ESTBR), Université Polytechnique d'Abomey \\ (UPA), Abomey, Benin \\ Email: *ahlinhan@yahoo.fr
}

Received 18 April 2016; accepted 10 June 2016; published 13 June 2016

Copyright @ 2016 by authors and Scientific Research Publishing Inc.

This work is licensed under the Creative Commons Attribution International License (CC BY).

http://creativecommons.org/licenses/by/4.0/

(c) (i) Open Access

\section{Abstract}

The knowledge of the internal stability of granular soils is a key factor for the design of granular and filter for the geotechnical infrastructures such as dykes, barrages, weirs and roads embankment. To evaluate the internal instability of granular soils different criteria are generally used in the practice. However, the results of these criteria on the same soil may lead to different evaluations of the internal instability. In this paper the common criteria used for the internal instability have been presented and compared as far as possible. It was found that the most internal instability criteria define a limit value for the secant slope of the grain size distribution curve of the granular soils. Based on this finding an own criterion for the evaluation of the internal instability of granular soil has been developed and compared to the common criteria. A very good agreement between some criteria was found. Furthermore, a site specific assessment for the evaluation of the internal instability of granular soil has been proposed in order to get more confidence in this evaluation.

\section{Keywords}

Internal Instability, Granular Soils, Seepage, Dams, Dykes, Site Specific Assessment, Instability Index

\section{Introduction}

Internal instability or suffusion is a failure mode of the soil subjected to seepage. This failure mode is characterized by the wash out of the fine fraction through the pore matrix of the coarse fraction of the soil. The results are segregation in soil, a modification of the drainage properties, possible increase of the soil permeability of the

\footnotetext{
*Corresponding author.
}

How to cite this paper: Ahlinhan, M.F., Koube, M.B. and Adjovi, C.E. (2016) Assessment of the Internal Instability for Granular Soils Subjected to Seepage. Journal of Geoscience and Environment Protection, 4, 46-55. 
porosity of the bulk density, and of the pore pressure. As consequence the resistance of the soil against external load decreases and the settlement increases.

Likewise, all drainage solutions become inefficient with the time due to migration of fine grains also internal instability or piping, Chapuis (1992) [1]. Therefore, the internal instability of soil is an essential problem for the long term stability of earth structures (dykes, dams, weirs, road embankment) subjected to seepage. According to Foster et al. (2000) [2] internal erosion and piping are a significant cause of failure and accidents affecting embankment dams.

To assess whether internal instability or suffusion is possible, two criteria i.e. the geometric criterion and the hydraulic criterion have to be fulfilled. For the geometric criterion, the proof consists to check whether it is possible that fine grains are able to pass through the smallest constrictions along the relevant pore path of coarse soil fraction without clogging. For that, the geometry of the pore channels has to be considered. Since the pore channel geometry cannot be exactly measured, the assessment is generally based on the curve of the grain size distribution, which is related to the pore channel geometry.

When the geometric criterion shows that the migration of fine fraction of the soil is possible, it has to be checked whether the hydrodynamic load in the pore structure provides a critical energy to mobilize and to transport fines grains (hydraulic criteria). Only the geometric criteria have been dealt in this paper, for the hydraulic criteria reference is made to Ahlinhan (2011) [3] and Ahlinhan et al. (2010) [4].

The geometric criteria for the internal instability can be classified in three categories as follows:

- the geometric criteria based on the pore constriction size

- the geometric criteria based on filter rules, and

- the geometric criteria based on comparison between the curve of the grain size distribution of the soil concerned and the curves of the grain size distribution of theoretical stable soils.

The above mentioned criteria are presented (Section 2 to Section 4) and compared (Section 5). Then, a resultant geometric criterion is developed in Section 6. Moreover a site specific assessment for the internal instability is proposed in Section 7.

\section{Criteria Based on the Pore Constriction Size}

A simple geometric criterion for the internal stability of granular soils is the requirement that the pore diameter $d_{p}$ shall be smaller than the smallest grain diameter $d_{\min }$.

$$
d_{p}<d_{\text {min }}
$$

Kovacs (1981) [5] proposed a geometric criterion for the internal stability given in Equations (2) and (3), which were based on the capillary tubes model. The capillary tubes model supposes a hydraulic similarity between the network of the pore channel and the capillary tubes. The conduits of the pore channels are supposed to be parallel to the seepage direction as shown in Figure 1.

$$
d_{1}<d_{\min } \Rightarrow 2.7 \cdot \frac{n}{1-n} \cdot \frac{d_{h}}{\alpha}<d_{\min }
$$

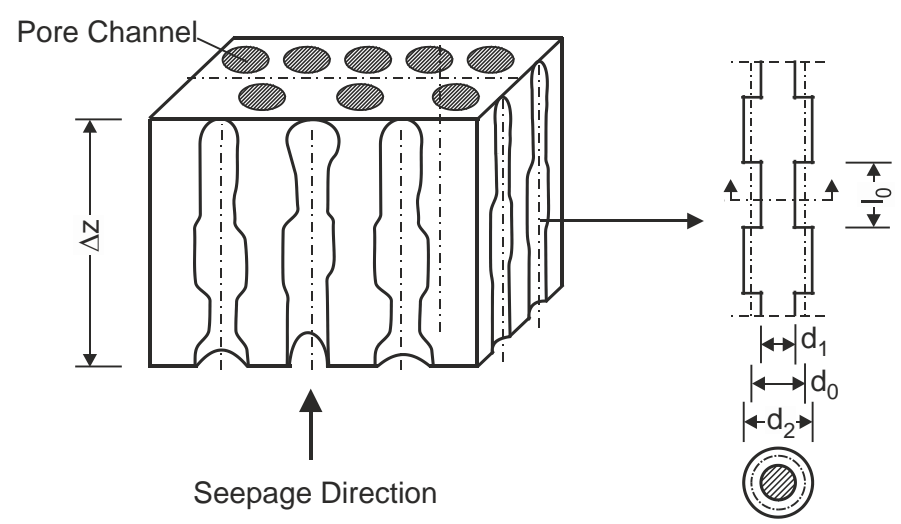

Figure 1. Capillary tubes model as per Kovacs (1981) [5]. 
or

$$
d_{0}<d_{\min } \Rightarrow 4.0 \cdot \frac{n}{1-n} \cdot \frac{d_{h}}{\alpha}<d_{\min }
$$

Here, $n$ is the porosity, $d_{h}$ is the effective grain diameter, $\alpha$ is the shape factor and $d_{0}$ is the mean diameter of the channels. Equations (2) and (3) show that the quotient of two grains diameters arbitrary of a grain size distribution curve e.g. $d_{h} / d_{\min }$ shall be smaller than a value depending on the porosity of the soil concerned.

Based on this approach, Istomina (1957)_cited in Busch et al. (1993) [6]_developed a geometric criterion for the suffusion considering the coefficient of uniformity $U$. For the suffusion stable soil the coefficient of uniformity $U$ shall be smaller than 10, for the suffusion unstable soil the coefficient of uniformity $U$ shall be larger than 20. Soil in transition zone fulfills following requirement: $10<U \leq 20$.

\section{Criteria Based on the Filter Rules}

The internal instability criteria based on the filter rules compare the ratio of mass percent for two grain diameters with a constant value. As explained above, internal stability is the detachment, and the transport of the fine grains of a soil through the grain skeleton formed by the coarse parts. It can be considered as a contact erosion process (i.e. the wash-out of a fine soil through the pores of an adjacent coarse soil layer) between the fine and coarse parts of the soil. Based on this consideration, Kezdi (1979) [7] proposed splitting up the grain size distribution of a soil into two grain size distributions, i.e. the fine and coarse parts, and assessing the stability by Terzaghi's well-known filter criterion applied to the two curves of the grain size distributions. This criterion, also known as Terzaghi's filter rule, is formulated as follows:

$$
d_{15 F} \leq 4 \cdot d_{85 b} \text {. }
$$

Here, $d_{15 F}$ is grain diameter for which $15 \%$ of the grains by weight of the coarse soil are smaller and $d_{85 b}$ is grain diameter for which $85 \%$ of the grains by weight of the fine soil are smaller.

The filter rule according to Sherard (1979) [8] is formulated as follows:

$$
d_{15 F} \leq 5 \cdot d_{85 b} \text {. }
$$

However, the Terzaghi criterion is valid only for poorly graded soil. To avoid this limitation, in the German guideline BAW (1989) [9] the splitting method is recommended in combination with the Cistin and Ziems contact erosion criterion (see Ahlinhan et al. 2010 [4]), which is also applicable to non-uniform soils. In general, the grain size distribution curve has to be split up at several points and the resulting fine and coarse soils have to be assessed with the contact erosion criterion given in Figure 2.

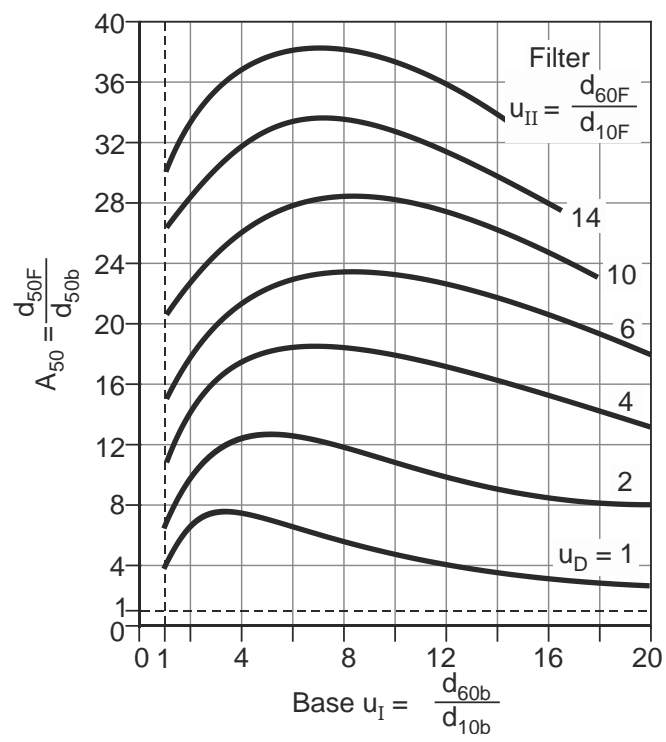

Boundary conditions:

Gradient in base soil i $<9$,

Base soil $0.1<\mathrm{d}<30 \mathrm{~mm}$,

Filter $4<\mathrm{d}<100 \mathrm{~mm}$,

Filter soil at least medium dense

state,

Base soil has to be stable with respect to suffusion,

Safety factor for distance ratio

A50: $\eta=1.5$

Figure 2. Filter criterion according to Cistin and Ziems (1968) in [9]. 
Burenkova (1993) [10] proposed a method based on results of laboratory tests on 22 granular soils of maximum size up to $100 \mathrm{~mm}$ and coefficient of uniformity $U$ up to 200 . Based on the three fractions $d_{15}, d_{60}$ and $d_{90}$, the internal stability of the soil was described by two ratios called conditional factors of uniformity $d_{90} / d_{60}$ and $d_{90} / d_{15}$. With these two factors of uniformity, Burenkova (1993) [10] presented boundaries between the suffusive soils and the non-suffusive soils as shown in Figure 3. Zone I and III represent suffusive granular soils, Zone II represents non-suffusive granular soils and Zone IV represents artificial soils. The zone for non-suffusive granular soils can approximately be expressed in function of the defined conditional factors of uniformity as follows:

$$
1+0.76 \cdot \log \left(d_{90} / d_{15}\right)<d_{90} / d_{15}<1+1.86 \cdot \log \left(d_{90} / d_{15}\right) .
$$

In addition to the criterion for suffusion, an approximate diameter $d_{d}$ dividing the suffusive and non-suffusive portion is also defined as follows:

$$
0.55 \cdot\left(d_{90} / d_{15}\right)^{-1.5}<d_{d} / d_{100}<1.86 \cdot\left(d_{90} / d_{60}\right)^{-1.5} .
$$

Wan and Fell (2008) [11] performed laboratory tests regarding internal instability of silt-sand-gravel and claysilt-sand-gravel soils. Based on the results of these tests and of tests by others researchers, Wan and Fell (2008) [11] described a method for assessing the potential, the probability of internal instability and a criterion of internal instability, which is shown in Figure 4.

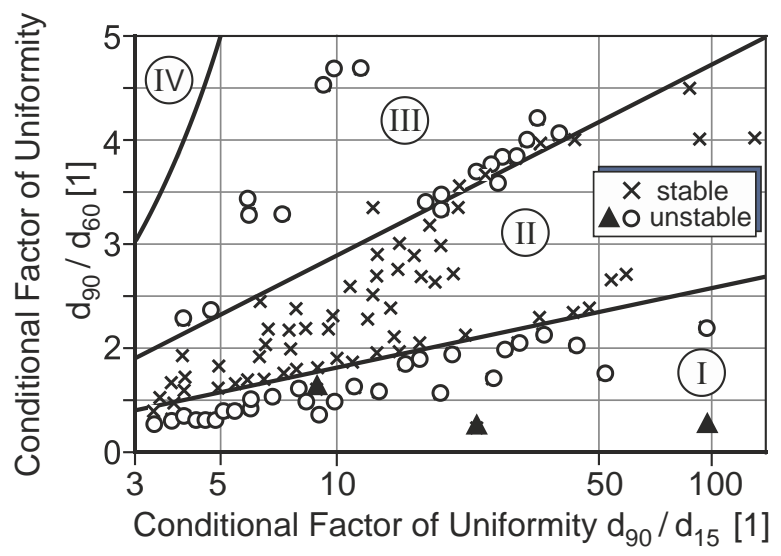

Figure 3. Suffusion criterion according to Burenkova (1993) [10].

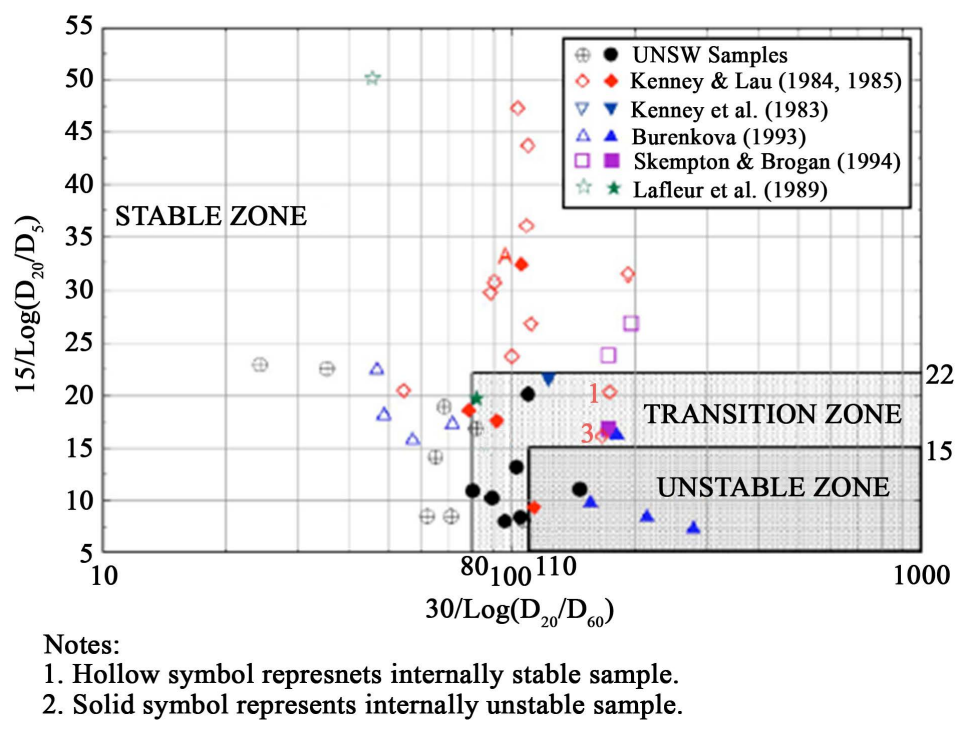

Figure 4. Alternative method for assessing internal instability of broadly graded silt-sand-gravel [16]. 


\section{Criteria Based on the Comparison with Theoretical Stable Soils}

Lubochkov (1965) — cited in Kovacs (1981) [5] — carried out laboratory tests regarding the suffusion and derived an analytical and graphical method for the proof of the internal instability. Grain size distributions lying between the borderlines given in Figure 5 can be considered as geometric stable soils regarding suffusion. Figure 5 shows also the well-known theoretical stable Fuller curve, which is generally applied for the formulation of granular for concrete. It can be seen that the Fuller curve lies in the middle of the borderlines.

Based on the laboratory tests Lubochkov (1965)—cited in Kenney and Lau (1985) [12]—established that the grading curve of a suffusion stable soil can be expressed as follows:

$$
F=0.60 \cdot\left(d / d_{60}\right)^{\frac{3}{5}} .
$$

Here, $d_{60}$ is the particle size for $60 \%$ mass percent, $d$ is an arbitrary particle size between $d_{0}$ and $d_{100}$, and $F$ is the masse percent of particles smaller than $d$.

Kenney and Lau (1985) [13] transformed the Equation (8) as follows:

$$
H=\left[4^{3 / 5}-1\right] \cdot F=1.3 \cdot F .
$$

Here, $H$ is the masse fraction between $d$ and $4 d$.

There was a particular reason for choosing the interval between $d$ and $4 d$. The size of the relevant constriction in a void network of a filter is approximately equal to one quarter of the size of particles for the filter, Kenney et al. (1985) [14] and Kenney et al. (1985) [13]. This means that particles of size $d$ can migrate through constrictions in a filter formed by particles of size $4 d$ or larger. To prevent such transport these constrictions would have to be clogged by particles larger than $d$. The value $H$, mass fraction of particles between sizes $d$ and $4 d$, provides some measure of the number of particles in a soil material that would form constrictions sufficiently small to prevent the passage of particles size $d$. For particles of size $d$ to be removed by seepage there must be a deficiency in the number of particles in the size range between $d$ and $4 d$, but if $H$ were sufficiently large, particles of size $d$ would not be transported.

The results of the laboratory tests performed by Kenney and Lau (1985) [13] confirmed the Equation (9). Therefore, Kenney and Lau (1985) [13] proposed transforming the grain size distribution curve to $F$ - $H$ diagram. Here $F$ is the mass percentage of grains with diameters less than a diameter $d$ and $H$ is the mass percentage of grains with diameters between $d$ and $4 d$ (Figure 6). A portion $F \leq 0.20$ of the grain size distribution has to be investigated for a widely graded soil, whereas a portion $F \leq 0.30$ of the grain size distribution is required for a narrowly graded soil. In Kenney and Lau (1985) [13] $H / F \geq 1.3$ was proposed as geometric internal stability criterion. In a following publication (Kenney and Lau 1986 [12]) based on the discussion by Milligan (1986) [15] and Sherard and Dunnigan (1986) [16], the less conservative requirement $H / F \geq 1.0$ was recommended for use.

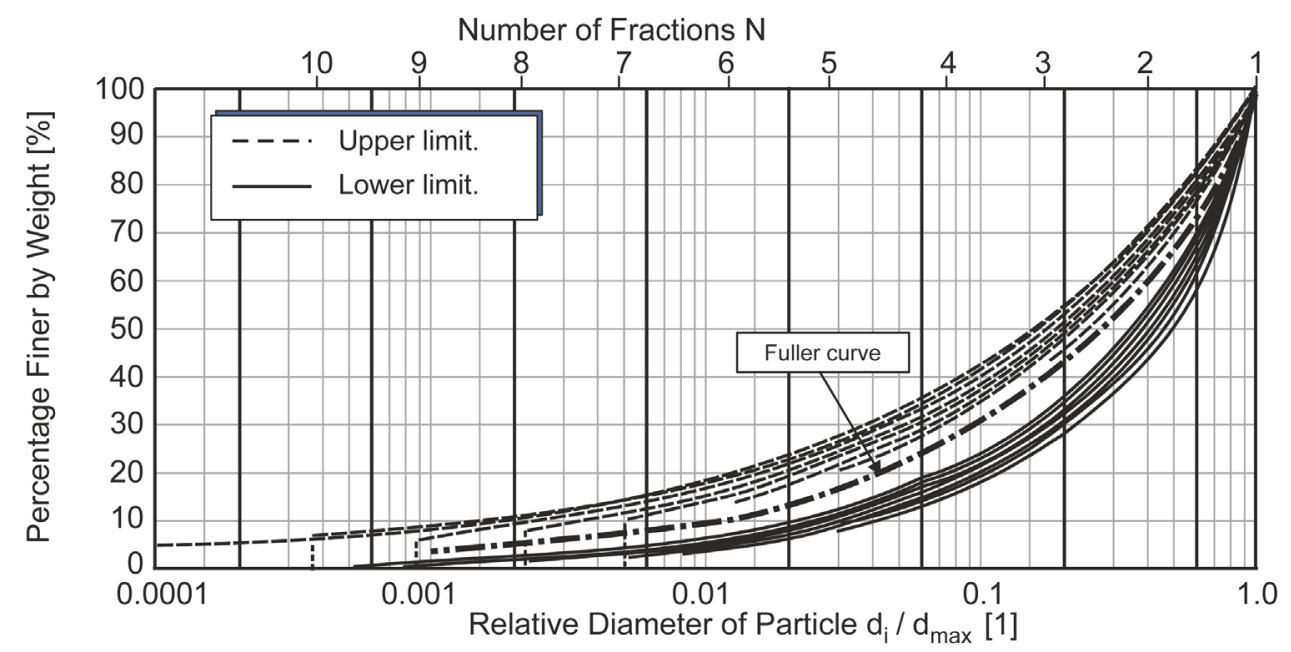

Figure 5. Borderlines for non-suffusive soils according to Lubochkov (1965). 

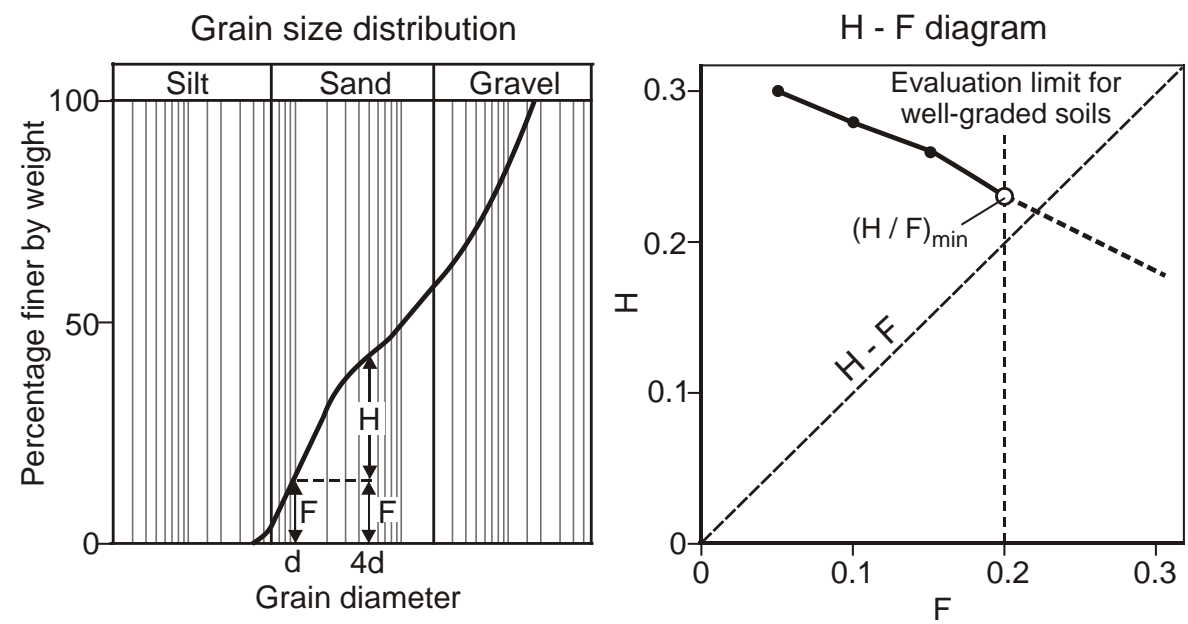

Figure 6. Geometric criterion for the internal stability according to Kenney et Lau (1985) [13].

\section{Comparison between the Criteria of Internal Instability}

Chapuis (1992) [1] demonstrated a mathematical similarity between the criteria for the internal instability. Here, these criteria for the internal instability were expressed as similar slope criteria. The slope of the grain size distribution curve at any point has been approximated by the slope of the secant line. Then, the secant slope of the grain size distribution curve indicates the risk of the internal stability.

Let us call $I$ the point at which the grain size distribution curve is divided in fine and coarse fraction (Figure 7).

The mass percentage for particle size smaller than the size $d_{I}$ is called $y_{I}$. In the fine portion, the abscise of the point $J$ is $x_{J}=\log d_{85 b}$ and its masse percentage is $y_{J}=0.85 y_{I}$. In the coarse portion, the abscise of the point $K$ is to $x_{K}=\log d_{15 F}$ and its mass percentage is:

$$
y_{K}=15 \% \cdot\left(100 \%-y_{I}\right)+y_{I}=85 \% \cdot y_{I}+15 \%
$$

The secant slope $s_{J K}$ between the points $J$ and $K$ can be expressed as:

$$
\begin{gathered}
s_{J K}=\frac{y_{K}-y_{J}}{x_{K}-x_{J}} \\
s_{J K}=\frac{0.15}{\log \left(d_{15 F} / d_{85 b}\right)}
\end{gathered}
$$

Equation (4) in Equation (12) can be expressed as follows:

$$
s_{J K} \geq \frac{0.15}{\log 4}=24.91 \%
$$

In a similar way the Kenney and Lau (1985) [13] criterion can be expressed as follows:

$$
s_{L I} \geq \frac{y_{L}-y_{I}}{x_{L}-x_{I}}=\frac{(F+H)-F}{\log 4 d-\log d}=\frac{H}{\log 4}=1.66 \cdot H
$$

Therefore, the Kezdi (1979) [7] criterion is equivalent to the following: if a soil has in its grain size distribution curve a slope larger than $24.91 \%$ per cycle, it will be able to stabilize its own particles finer than the grain size at which such slope occurs (see equation 13). Likewise, the Kenney and Lau (1985) [13] method is equivalent to the following: at a particle size $d_{y}(y \leq 20 \%)$, the slope per cycle of the grain size distribution curve must be larger than $1.66 \cdot \mathrm{H}$ to have internal stability.

The criteria based on the filter rules compare the slope of the grain size distribution curve with a constant value $24.91 \%$ by the Kezdi (1979) [7] criterion and $21.45 \%$ by Sherard (1979) [8] criterion, whereas the criteria based on the Kenney and Lau (1985) [13] criterion compares the slope of the grain size distribution curve with a value which depends on the mass percentage. 


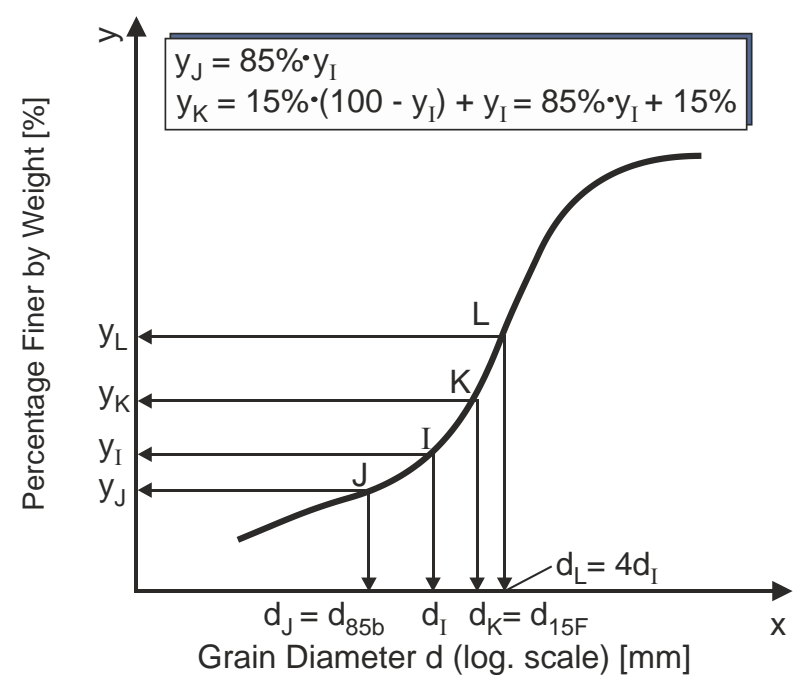

Figure 7. Illustration for the determination of the mass percentage of $d_{85 b}$ and $d_{15 F}$.

\section{Proposed Approach to Assess the Internal Instability of Granular Soil}

Theoretical considerations were made in order to define the point at which the split-up of the curve of the grain size distribution should be carried out. In general, the grain size distribution might be split at several points. For the illustration of the splitting up approach in Figure 8 two points $T_{1}$ and $T_{2}$ have been exemplary considered. The steeper the grading curve, the smaller is the distance $b$ between fine and coarse fraction obtained from the splitting up of the grain size distribution curve at a point $T$ (Figure 8). A maximum distance $b$ between the fine fraction (base) and the coarse fraction (filter) represents the worst case scenario for the geometric stability of the soil. The secant slope $\beta$ between a horizontal axis and the grading curve at the split-off point $T$ can be expressed as follows:

$$
\tan \beta=\frac{H}{\log 4 d-\log d}
$$

Here, $d$ is the particle diameter at the split-off point $T, F$ the mass fraction of particles smaller than $d$ and $H$ the mass fraction of particles between $d$ and $4 d$. If $b$ is maximal, $\beta$ is minimal, and then $H$ also becomes minimal. Therefore, it is proposed to split the grading curve at $(H / F)_{\min }$. The associated filter quotient is denoted as a modified filter or instability index $\left(d_{15 /} / d_{85 b}\right)_{\text {mod }}$. The point $(H / F)_{\min }$ represents a "weak point" for the soils and is therefore relevant for the assessment of its geometric stability. For internal stable soil the instability index $\left(d_{15 f} / d_{85 b}\right)_{\text {mod }}$ shall be smaller than 4, Ahlinhan [3].

The above mentioned criteria for the internal stability cannot generally be compared with each other except the criteria based on filter rules and the Kenney and Lau (1986) criterion [12]. Therefore, five (5) granular soils with grain size distribution curves shown in Figure 9 have been selected and analyzed regarding the internal instability criteria. The geometric parameters such as $H, F$, and $d_{x \%}$ can be derived from the grain size distribution curves.

The geometric criteria after Kezdi (1979) [7] and Kenney and Lau (1985) [12] are depicted in Figure 10, our own test results and the test results of several authors regarding the internal stability of soils are presented [3]. Figure 10 shows that all soils with points lying above the Kenney and Lau (1986) line are stable and all soils with points lying below the Kezdi (1979) line are unstable. Soils with points lying in the transition zone $(H>F$ $<0.15$ and $0.15<H<F$ ) can obviously be either stable or unstable depending on the hydrodynamic energy.

Table 1 summarizes the results of the internal instability analysis for the reference soils. The results of the confrontation of internal stability criteria in Table 1 show a general good agreement between the here proposed criterion and the criteria as per Lubochkov (1965), Kenney and Lau (1986) and BAM MSD (1989). However, these four criteria do not lead to the same prediction of the internal instability for the soil E1. This could be explained by the specific limit of boundary for each criterion, which has to be considered in a framework of the assessment of internal stability. 


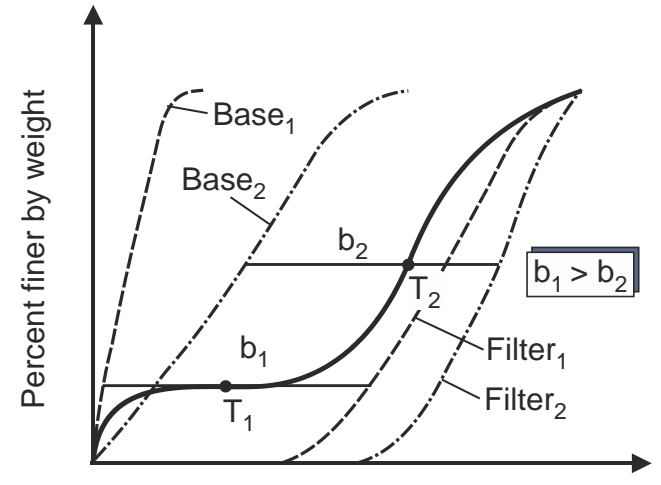

Grain diameter d [mm]

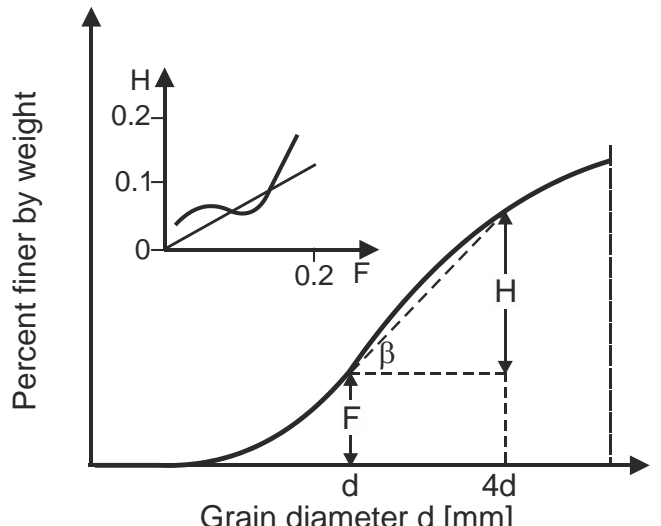

Grain diameter d [mm]

Figure 8. Illustration for the determination of the mass percentage of $d_{85 b}$ and $d_{15 F}$.

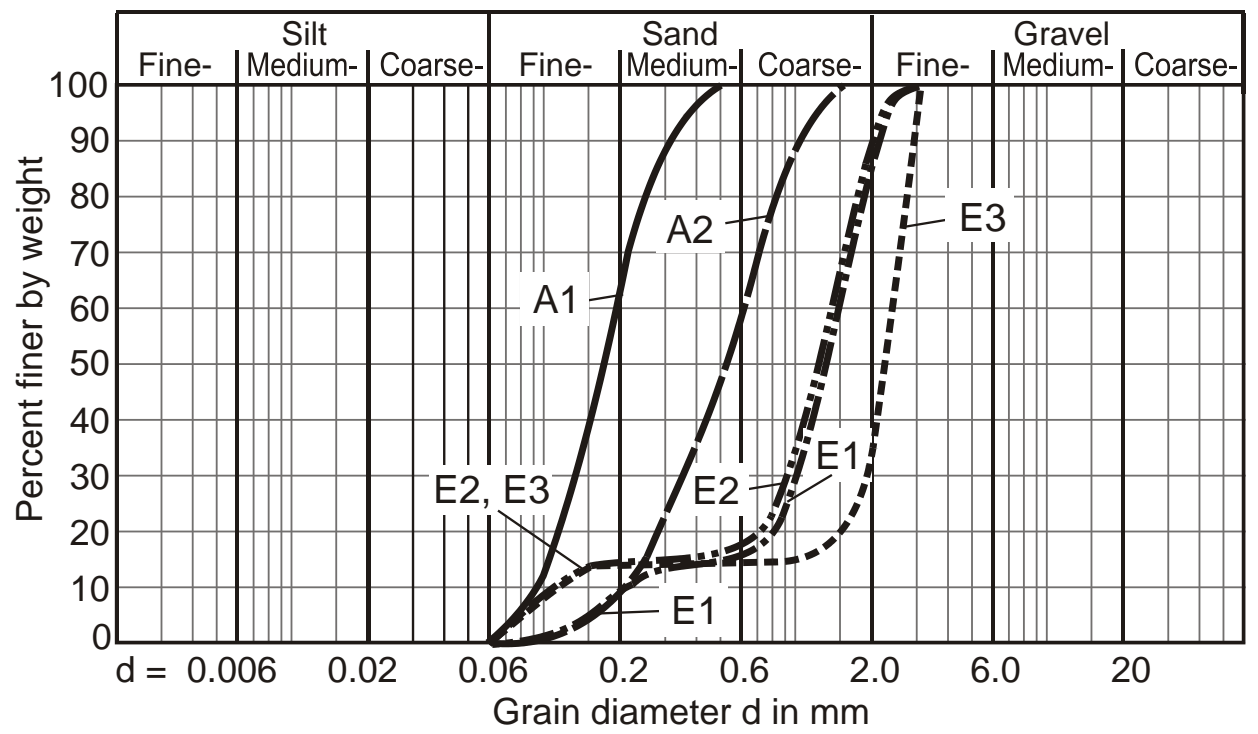

Figure 9. Grain size distribution curves of the reference soils.

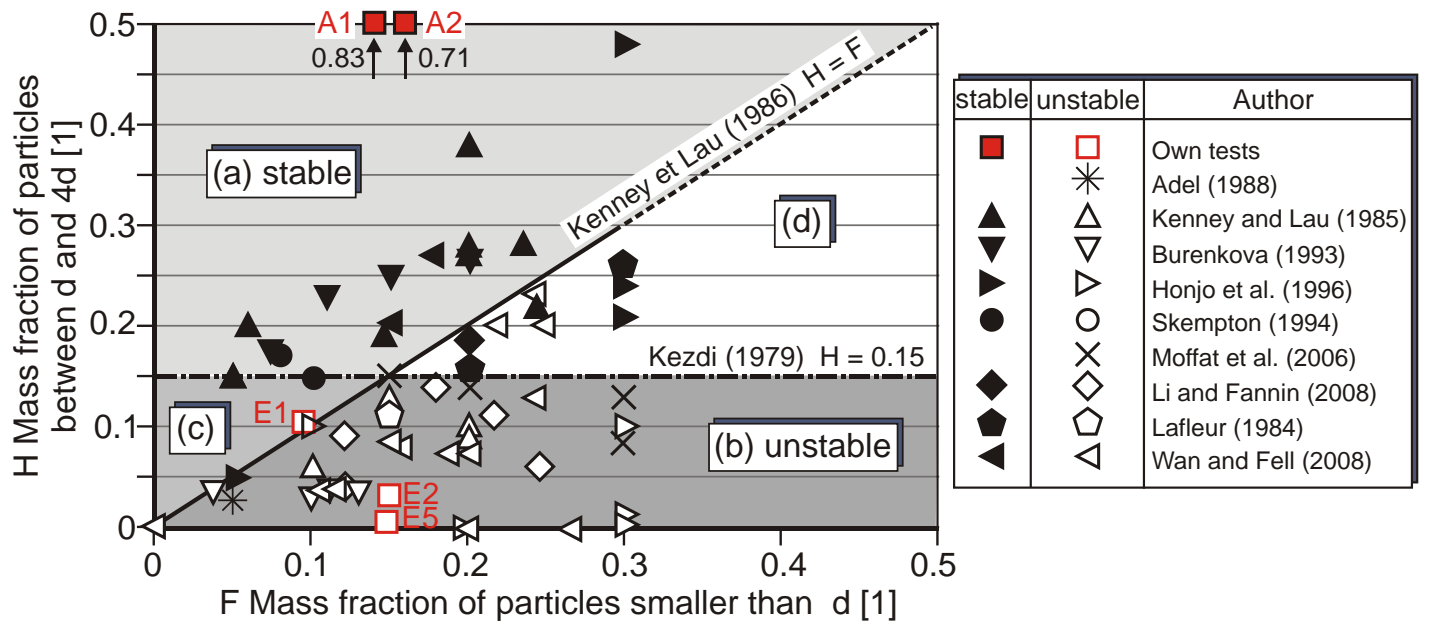

Figure 10. Compilation of the test results regarding internal instability of granular soil [3]. 
Table 1. Evaluation results of the geometric internal stability for the reference soils.

\begin{tabular}{|c|c|c|c|c|c|}
\hline \multirow{2}{*}{ Parameters/criteria } & \multicolumn{5}{|c|}{ Reference soils } \\
\hline & $\mathrm{A} 1$ & A2 & E1 & E2 & E5 \\
\hline Coefficient of uniformity $U$ & 2.10 & 3.00 & 6.80 & 13.50 & 23.40 \\
\hline Ratio $(H / F)_{\min }$ & 2.92 & 3.23 & 1.10 & 0.20 & 0.03 \\
\hline$\left(d_{15 F} / d_{85 b}\right)_{\bmod }$ & 1.21 & 1.41 & 3.80 & 7.20 & 13.84 \\
\hline Istomina (1957) & $\mathrm{S}$ & $\mathrm{S}$ & $\mathrm{S}$ & $\mathrm{S} / \mathrm{U}$ & $\mathrm{U}$ \\
\hline Cistin (1965) & S & $\mathrm{S}$ & $\mathrm{S}$ & $\mathrm{U}$ & U \\
\hline Lubochkov (1965) & $\mathrm{S}$ & $\mathrm{S}$ & $\mathrm{U}$ & $\mathrm{U}$ & $\mathrm{U}$ \\
\hline Kezdi (1979)@(H/F)min & $\mathrm{S}$ & $\mathrm{S}$ & $\mathrm{S}$ & $\mathrm{U}$ & $\mathrm{U}$ \\
\hline Sherard (1979) @ $(H / F)_{\min }$ & $\mathrm{S}$ & $\mathrm{S}$ & $\mathrm{S}$ & $\mathrm{U}$ & $\mathrm{U}$ \\
\hline De Mello (1975)@ $(H / F)_{\min }$ & $\mathrm{S}$ & $\mathrm{S}$ & $\mathrm{S}$ & U & U \\
\hline Kenney et Lau (1986) & $\mathrm{S}$ & $\mathrm{S}$ & $\mathrm{S}$ & $\mathrm{U}$ & $\mathrm{U}$ \\
\hline BAW MSD (1989) @ $(H / F)_{\min }$ & $\mathrm{S}$ & $\mathrm{S}$ & U & U & U \\
\hline Proposed method & $\mathrm{S}$ & $\mathrm{S}$ & $\mathrm{S} / \mathrm{U}$ & $\mathrm{U}$ & $\mathrm{U}$ \\
\hline
\end{tabular}

Legend: S for geometric Stable; U for geometric Unstable; S/U geometric Stable or Unstable (transition zone).

\section{Site Specific Assessment (SSA) for the Internal Instability}

A site specific assessment regarding internal stability is recommended for the construction or the rehabilitation of dykes, barrages, weirs, road embankment, etc. To carry the site specific assessment the environmental data such as water depth, seepage condition, seepage velocity, hydraulic gradient are required. These environmental data are the effect of action. Moreover the site specific geotechnical data, which are the resistance, must be considered. The type and amount of the geotechnical data required will depend on the particular circumstances such as the type of the geotechnical infrastructure (dykes, barrages, weirs, road embankment, etc.) and previous experience of the site, or nearby or similar sites, for which the assessment is being performed. Such geotechnical information includes shallow seismic survey, coring data, cone penetrometer tests, side-scan sonar, magnetometer survey and diver's survey. The environmental and geotechnical data have to be considered for the evaluation of the internal stability of the soil as follows:

1) Carry out analysis regarding the susceptibility to internal stability by applying relevant criteria, e.g. Ahlinhan et al. (2011) [3], Kenney and Lau (1986) [12] Kezdi (1979) [7] and Lubochkov (1965) [5]. The Interpretation of the results of this analysis has to be performed with sound engineering judgment.

2) Take reasonably into account the complex soil structure, its variability its non-homogeneity (layered soils, soils variability, etc.) for some laboratory tests regarding the internal instability.

3) Compare the results from (1) and (2) in order to get more confidence for the assessment of the internal stability.

For economic reason the unstable soils may be used in the practice. For that, it has to be proved that hydrodynamic energy i.e. the hydraulic gradient and the velocity of the seepage will not reach the critical one.

\section{Conclusions}

The main criteria for the internal instability of the granular soil subjected to seepage have been presented and compared. These main criteria can be classified in three categories, i.e. the criteria based on the pore distribution or constriction size, the criteria based on filter rules, and the criteria based on the comparison of the grain size distribution curve with the grain size distribution curve of a theoretical stable soil. The comparison shows that the criteria based of filter rules (e.g. Sherard (1979) [8], and Kezdi (1979) [7]) and the criteria based the criteria based on the comparison of the grain size distribution curve with the grain size distribution curve of a theoretical stable soil (e.g. Lubochkov (1969) in [5], Kenney et Lau (1986) [12]) can be replaced by minimum value for the secant slope of the grain size distribution curve. The criteria based on the filter rules compare the secant slope of 
the grain size distribution curve with a constant value (24.91\% by the Kezdi (1979) [7] criterion and 21.45\% by Sherard (1979) [8] criterion. But the criteria based on the comparison of the grain size distribution curve of the soil concerned with the grain size distribution of theoretical stable soil compare the secant slope of the grain size distribution curve with a value which depends on the mass percentage. A good agreement between the proposed criterion and the common criteria has been observed for the splitting of the grain size distribution curve at $(H / F)_{\min }$. It should be noted that these geometric criteria are based on the resistance that means the pore distribution or the constriction size or the grain size distribution curve of the soil, but not the effect of action or the loading that means the seepage velocity, the hydraulic gradient. Therefore, combined geometric and hydraulic criteria will be an economical design approach, since unstable soils are often used in the practice, when the hydrodynamic energy, the hydraulic gradient, and the seepage velocity are lower than the critical one.

Moreover, a site specific assessment regarding the internal stability has been proposed for engineering practice. Hence, this paper presents a practical approach to analyze the geometric internal instability. However, a development of a software tool which would consider the grain size distribution curve (resistance) and the hydrodynamic energy (effect of action), would be very helpful for the design and analysis with respect to the internal instability.

\section{Acknowledgements}

This research was partially supported by the Germany Ministry of Education and Research through IPSWaT (International Postgraduate Studies in Water Technologies). This support is gratefully acknowledged.

\section{References}

[1] Chapuis, R.P. (1992) Similarity of Internal Stability Criteria for Granular Soils. Canadian Geotechnical Journal, 29, 711-713. http://dx.doi.org/10.1139/t92-078

[2] Foster, M., et al. (2000) A Method for Assessing the Relative Likelihood of Failure of Embankment Dams by Piping. Canadian Geotechnical Journal, 37, 1025-1061. http://dx.doi.org/10.1139/t00-029

[3] Ahlinhan, M.F. (2011) Investigation of the Internal Stability of Non-Cohesive Soils. Ph.D. Thesis, Leibniz University Hannover, Germany. (In German)

[4] Ahlinhan, M.F. and Achmus, M. (2010) Experimental Investigation of Critical Hydraulic Gradients of Unstable Soils. Scour and Erosion, 5, 599-608. http://dx.doi.org/10.1061/41147(392)58

[5] Kovacs, G. (1981) Seepage Hydraulics. Elsevier Scientific Publishing Company, Amsterdam; Oxford, New York.

[6] Busch, K.-F., Luckner, L. and Tiemer, K. (1993) Geohydraulik. In: Matthess, G., Ed., Gebrüder Bornträger, Berlin, Stuttgart, 3. Neubearbeitete Auflage.

[7] Kezdi, A. (1979) Soil Physics. Elsevier Scientific Publishing Company, Amsterdam; Oxford, New York.

[8] Sherard, J.L. (1979) Sinholes in Dams of Coarse, Broadly Graded Soils. Transactions, 13th International Congress on Large Dams, New Delhi, Vol. 2, 25-35.

[9] BAW (1989) Merkblatt Anwendung von Kornfiltern an Wasserstraßen (MAK). Bundesanstaltfür Wasserbau, Ausgabe.

[10] Burenkova, V.V. (1993) Assessment of Suffusion in Non-Cohesive and Graded Soils. In: Brauns and Schüler, Eds., Filters in Geotechnical and Hydraulic Engineering, Balkema, Rotterdam, 357-360.

[11] Wan, C.F. and Fell, R. (2008) Assessing the Potential of Internal Instability and Suffusion in Embankment Dams and Their Foundations. Journal of Geotechnical and Geoenvironmental Engineering, 134, 401-407. http://dx.doi.org/10.1061/(ASCE)1090-0241(2008)134:3(401)

[12] Kenney, T.C. and Lau, D. (1986) Internal Stability of Granular Filters: Reply. Canadian Geotechnical Journal, 23, 420-423. http://dx.doi.org/10.1139/t86-068

[13] Kenney, T.C. and Lau, D. (1985) Internal Stability of Granular Filters. Canadian Geotechnical Journal, 22, $215-225$. http://dx.doi.org/10.1139/t85-029

[14] Kenney, T.C., Chahal, R., Chiu, E., Ofoegbu, G.I., Omange, G.N. and Ume, C.A. (1985) Controlling Constriction Sizes of Granular Filters. Canadian Geotechnical Journal, 22, 32-43. http://dx.doi.org/10.1139/t85-005

[15] Milligan, V. (1986) Internal Stability of Granular Filters: Discussion. Canadian Geotechnical Journal, 23, 414-418. http://dx.doi.org/10.1139/t86-066

[16] Sherard, J.L. and Dunnigan, L.P. (1986) Internal Stability of Granular Filters: Discussion. Canadian Geotechnical Journal, 23, 418-420. http://dx.doi.org/10.1139/t86-067 